\title{
ORIGEM E DESENVOLVIMENTO LÓGICO DO DINHEIRO: CONTROVÉRSIAS MARXISTAS
}

Giliad de Souza Silva1

\section{INTRODUÇÃO}

O dinheiro é compreendido pelo programa de pesquisa marxista como desdobramento da natureza dos produtos do trabalho enquanto mercadorias, assim como do caráter da economia organizada para a produção de mercadorias. Por isso que, para entender o dinheiro, na teoria marxista, necessário se faz partir do estudo das relações basilares da economia e não iniciar pela análise de seus atributos e funções. O dinheiro é uma necessidade lógica, social e econômica, derivada do caráter intrínseco da mercadoria, assim como do trabalho que a produz, a saber, a dualidade entre trabalho concreto, produtor de valores de uso, e trabalho abstrato, trabalho comum, produtor do valor (BORGES NETO, 2001, p.11-2).

Um passo inicial para entender o dinheiro é defini-lo, enquanto forma material de aparência do valor ou riqueza abstrata e expressa o caráter social da troca. Ou seja, vai muito além de um mero signo de facilitação das trocas ou uma imposição legal do Estado, como compreende a teoria convencional. Não obstante, qualquer teoria que explique o dinheiro deve apontar como ele surge logicamente e se desenvolve nos marcos do capitalismo, assim como a diferença entre as trocas diretas e as trocas multilaterais, no sentido de enfatizar a importância econômica do dinheiro. É por ter este pressuposto que o programa de pesquisa marxista se coloca em melhores condições de entender os fenômenos monetários, tantos os pretéritos quanto os atuais, se comparado à abordagem econômica convencional.

Este trabalho objetiva comparar a leitura de diversos intérpretes marxistas que trabalham com a categoria dinheiro, em sua noção mais basilar. Ademais, objetiva também delimitar um espaço teórico para a exposição de uma teoria monetária especificamente marxista, assim como mostrar o atual estado das artes desta teoria. Para isso, necessário se faz localizar as aproximações conceituais, assim como as divergências existentes, sobretudo entendendo a formulação dos autores a respeito da origem lógico-histórica do dinheiro, mediante a definição do conceito, o que se entende por valor e mercadoria e a relação do dinheiro no processo de troca.

Para tanto, o caminho aqui percorrido não apenas apontou o que fala cada intérprete, porém "os colocou para dialogar". Só assim foi possível apresentar as similitudes e dissimilitudes

\footnotetext{
${ }^{1}$ Professor Adjunto C da Universidade Federal do Sul e Sudeste do Pará (Unifesspa). Membro do corpo docente da Faculdade de Ciências Econômicas (FACE/Unifesspa) e ao Programa de Pós-Graduação em Planejamento e Desenvolvimento Regional e Urbano na Amazônia (PPGPAM/Unifesspa). E-mail: giliad.souza@unifesspa.edu.br
} 
dos argumentos dos diversos autores, os elementos que conformavam as respectivas abordagens e as lacunas teóricas ainda persistentes. É por isso que no corpo do texto, as impressões apresentadas pelo autor deste trabalho encontram-se resumidas na "conclusão". Em resumo, 0 objetivo prioritário desde texto não é apresentar um ponto de vista próprio, mas sim expor as posições mais significativas já existentes sobre a questão do dinheiro.

Ademais, este trabalho está estruturado da seguinte forma: para além desta breve introdução e da conclusão, existem quatro partes; a primeira, que expõe como o dinheiro é definido, nos marcos da teoria marxista, assim como a relação social que ele expressa, isto é, a relação vendedor-comprador e sua origem conceitual na teoria do valor; a segunda, tendo em vista que já se sabe o modo categorial de onde o dinheiro derivado, mostrará como os marxistas compreendem tanto o valor e suas dimensões, assim como a natureza da mercadoria; a terceira, que exporá a distinção feita pelo marxismo entre as trocas diretas e as trocas multilaterais e como o dinheiro se origina e se desenvolve dentro desta e; a quarta, que tem o caráter de mostrar uma discussão sobre a existência de uma teoria quantitativa do valor, ainda nos marcos teóricos que antecedem o dinheiro. Esta discussão é basicamente entre Reuten e Moseley.

\section{DEFININDO DINHEIRO}

Um passo importante para o entendimento da abordagem marxista da teoria monetária é compreender o que se define por dinheiro. Dinheiro, para Cutler (1981, p.20) "é um signo porque expressa o caráter social da troca", é um espelho que reflete o valor de uma mercadoria, como afirma Murray (2005, p.50), "o modo de ser material da riqueza abstrata", segundo Germer (1997, p.109) ou ainda, a personificação objetiva do trabalho abstrato (SHUKLIAN, 2000, p.10). Foley $(1983$, p.7) diz que o dinheiro tem a capacidade de expressar o tempo de trabalho numa sociedade produtora de mercadorias. Para Astarita (2006, p.3), "dinero es encarnación del valor, material en que se validan los trabajos privados". Moseley $(2010$, p.4), por sua vez, define o dinheiro como a forma necessária da aparência da substância do valor, no caso o trabalho abstrato objetivado. Assim, o dinheiro é tratado, conforme Nelson (2005, p.67), como algo fundamental para o mundo as mercadorias, que é regulado pela lei do valor.

Segundo Itoh e Lapavitsas (1999, p.33) e Brunhoff (2005, p.209), o dinheiro, no marxismo, é compreendido num sentido diametralmente oposto à teoria convencional, não sendo apenas uma facilitação às trocas ou uma unidade de conta, ou ainda tendo o seu valor determinado pela sua quantidade em circulação. Para abordagem convencional, como afirma Shuklian (2000, p.1), "money is nothing more than a technical convenience that human beings have 'invented' to 
overcome the difficulties associated with barter". Para Itoh e Lapavitsas (1999, p.33) e Lapavitsas (2005, p.401), esta seria uma das razões da abordagem convencional não entender o "mistério" e complexidade do dinheiro, sobretudo porque ele é simultaneamente relação social e uma "coisa" e monopoliza da capacidade de troca frente a todas as outras mercadorias. Esse mistério é solucionado baseando-se na distinção feita por Marx entre as dimensões do valor, sobretudo a substância e forma.

O programa de pesquisa marxista procura definir dinheiro não como um signo que é totalmente produzido pela convenção social e se encarna no Estado, posto que, se assim o fosse, chegar-se-ia a conclusão de que não há valor, do ponto de vista substantivo, sendo este determinado unicamente na troca. Isto evidentemente iria de encontro não apenas com a abordagem de Marx, como também a toda contribuição da Economia Política. Por isso, é imperativo afirmar que ele surge não como um evento ocasional ou isolado dentro do plano de fundo da formação econômico-social capitalista. Assim, o dinheiro é entendido como condição prévia, tanto para a emergência quanto para o desenvolvimento pleno da produção capitalista. Embora as implicações da existência dele estejam vinculadas ao processo de circulação, elas seguem para além deste, na medida em que precede e segue tanto a produção como o consumo de mercadorias (PAULANI, 2011, p.62; CARVALHO, 2011, p.27; CUTLER, 1981, p. 56).

Nesse sentido, Klagsbrunn (1993, p.594) afirma que o dinheiro é uma categoria que deve ser explicada, não apenas demonstrando seu surgimento histórico, porém desenvolvendo suas leis imanentes, no qual a história lhe é basilar. $E$ isto é que Marx objetiva, nas suas obras "econômicas", e o marxismo o tem como ponto de partida. Isto posto, Germer (1997, p.108) e Lapavitsas (2005, p.400) expõem que o dinheiro, embora seja uma "coisa", exprime relações econômicas definidas e distintas entre indivíduos. Afirmar, com isso, que ele traduz uma determinada relação social significa dizer que o dinheiro representa uma relação social materializada e convertida em determinado objeto, ou seja, estabelece a expressão material de uma relação econômica entre vendedores e compradores. Esta relação, diz Brunhoff (1978, p.156), que se manifesta exclusivamente na produção mercantil e exprime a circulação de mercadorias e dinheiro, é determinada por uma relação social geral, a saber, "a troca privada supõe a produção privada". Na medida em que o dinheiro exprime a relação vendedor/comprador, isto é, a "relação geral de troca entre agentes econômicos privados, a economia monetária é comum a toda produção de mercadorias". Assim, Lapavitsas (2005, p.390) afirma que,

the social relations that constitute money are those among commodity owners engaging in exchange. These relations unfold out of initial contacts between commodity owners that take the form of 'making a request for exchange - receiving the ability to exchange 
directly'. Money subsequently monopolizes the ability to exchange directly (buy), and thus acts as social nexus among commodity owners.

Numa economia mercantil, o dinheiro é uma necessidade derivada das relações sociais de produção. Do ponto de vista analítico, deriva-se da teoria do valor. Moseley (2005, p.1) assevera que a teoria monetária marxista explica a necessidade do dinheiro baseado nos fundamentos da teoria do valor. A teoria do dinheiro pressupõe e é integrada a teoria do valor. Segundo Murray (2005, p.51), para compreender dinheiro necessário se faz localizá-lo imbrincado teoricamente ao valor, pois, ao passo que o trabalho privado valida-se socialmente apenas através da venda dos seus produtos, valor e dinheiro tornam-se inseparáveis, ainda que não idênticos e não relacionáveis enquanto variável dependente-independente. Por isso, Shuklian (2000, p.10) afirma que a teoria do valor de Marx foi desenvolvida vis-à-vis a do dinheiro, havendo assim, uma forte conexão entre as dimensões do valor e o dinheiro. Nelson (2001, p.44), por sua vez, menciona que a teoria do dinheiro, na economia política, surge constituindo a teoria do valor trabalho. Para ela, "money is an aspect of the commodity and market exchange".

\section{VALOR E MERCADORIA}

Tendo em vista que o valor assume um lugar diferenciado na teoria monetária marxista, é fundamental entendê-lo, sobretudo porque, na teoria do valor de Marx, as trocas de mercadorias implicam no valor mudando de forma, na troca de vários trabalhos envolvidos na sua produção (NELSON, 2005, p.67). Do ponto de vista analítico, segundo Foley (1983, p.5), o valor das mercadorias antecede o dinheiro, ou seja, o dinheiro só pode ser explicado, de acordo com Marx, apenas compreendendo o valor das mercadorias. Conforme Lapavitsas (2005, p.391), para compreender o dinheiro em sua plenitude, necessário se faz ter noção e situar a diferença entre as dimensões do valor para estabelecer o conteúdo econômico do "dinheiro em geral".

As trocas de mercadoria em proporções quantitativas determinadas pressupõe a existência de algum atributo qualitativo que as mercadorias compartilhem umas com as outras, no processo de troca. E este único atributo social que as mercadorias compartilham é o valor. $O$ valor é o nexo social que estabelece a relação entre os produtores, tendo como pressuposto a propriedade e a divisão social do trabalho. $O$ valor é o poder geral das trocas que reside nas mercadorias, enquanto expressão do trabalho despendido na sua produção. Assim, valor encontrado numa porção de mercadorias é proporcional à quantidade de trabalho gasto na sua produção. E o trabalho social ou abstrato é a sua substância, o tempo de trabalho abstrato contido em cada mercadoria implica na sua magnitude e a forma desse tempo de trabalho abstrato é 
expressa em valor de troca ou preço monetário, aparecendo, assim, o dinheiro como expressão ou materialização da forma observável do valor. Para tal categorização, Marx parte inicialmente da esfera da superfície aparente (valor de troca) para o domínio não observável da substância e magnitude (trabalho abstrato e tempo de trabalho socialmente necessário - TTSN), fazendo, como passo seguinte, o movimento lógico inverso, indo do domínio não observável da essência e magnitude do valor para sua forma superficial de aparência como dinheiro (FOLEY, 1983, p.6; SHUKLIAN, 2000, p.4-5; GERMER, 1997, p.110-1; MOSELEY 2010, p.3).

\footnotetext{
"Value" has three dimensions: substance, magnitude and form of appearance. However, it seems clear that "value" in this sentence refers to the substance and magnitude of value (abstract labor and socially necessary labor-time), which is invisible, but which is "ideally made perceptible" through equality with an imaginary quantity of gold that contains the same amount of abstract labor (MOSELEY, 2010, p.20).
}

A substância do valor, o trabalho abstrato, é média social do total dos trabalhos particularizados contida nas mercadorias. No entanto, essas mercadorias produzidas nos termos econômicos do capitalismo possuem também quantidades definidas dessa substância, ou seja, possui um dado volume ou magnitude de trabalho abstrato. Porém, essas quantidades não necessariamente correspondem à quantidade de trabalho privado individual realizada, ou seja, a magnitude não se relaciona absolutamente com as horas trabalhadas no concreto. Necessário de faz um processo de igualação ou reconhecimento social para definir a quantidade de trabalho socialmente necessário (GERMER, 1997, p.110-1; BORGES NETO, 2001, p.4).

Conjuntamente, é inegável que o valor possui uma forma, ou valor de troca, dotando, assim, as mercadorias de serem igualadas quantitativamente umas com as outras. Esse valor de troca é determinado pelas quantidades relativas de tempo de trabalho e sua alteração está em função das mudanças nas quantidades relativas do tempo de trabalho. Contudo, mesmo com 0 valor de troca, não é possível observar o tempo de trabalho que o valor expressa, carecendo a existência de uma forma material que o torne observável, que declare a quantidade de trabalho social contido na mercadoria. A forma do valor está ancorada na substância/magnitude do valor mediante diversos processos sociais e econômicos e o dinheiro surge como a forma material que torna o valor observável, porém não pela via da expressão direta do tempo de trabalho, mas pelo valor de troca ou preço, representado por determinada quantidade de dinheiro. Assim, o dinheiro, em Marx, é um produto material, trabalho abstrato alienado e objetivado, ou seja, é a materialização ou manifestação do trabalho abstrato. Porém, essa manifestação ocorre apenas de modo simbólico, já que nenhuma mercadoria nem o dinheiro pode expressar diretamente 0 trabalho social. Nesse sentido, o dinheiro surge diretamente do valor, e é sua forma independente 
e a mais desenvolvida. (GERMER, 1997, p.110-1; MOSELEY 2010, p.3 e 8; NELSON, 2001, p.59, FOLEY, 1983, p.5).

A teoria monetária marxista visa desenvolver e apreender as leis que lhe são próprias e imanentes. Decerto, a mercadoria é a origem lógica de onde parte esta teoria, pois ela é "a chave para dar um núcleo racional ao que seja o dinheiro" (KLAGSBRUNN 1993, p.594). Ela, que possui um duplo caráter (valor de uso e de troca), é um produto do trabalho humano que visa a venda, ou seja, é um não-valor de uso para o produtor e um valor de uso para o não-produtor. É por ela que o valor se expressa, se manifesta. $O$ valor é trabalho objetivado e alienado nas mercadorias, aparecendo na circulação como valor de troca e se tornando independente no dinheiro. Assim, 0 dinheiro é uma necessidade para as trocas mercantis ocorram, assim como para que se generalize a produção de mercadorias (KLAGSBRUNN 1993, p.594; BORGES NETO, 2001, p.2; NELSON, 2001, p.44).

Não é à toa que, do ponto de vista lógico, Marx fundamenta sua teoria monetária na mercadoria. Uma parte considerável de suas críticas aos socialistas franceses, conforme Nelson (2001), no tocante a questões monetárias, que os tornava iguais aos "apologistas burgueses" Bastiat e Carey, era a crença existente de que o dinheiro seria um instrumento da vontade das pessoas e os defeitos do sistema econômico remover-se-iam alterando o dinheiro enquanto tal. Por isso que, para ela, Marx, referenciado nos economistas políticos ingleses, parte logicamente da mercadoria, produto do trabalho abstrato, objetivado e alienado, para explicar a emergência do dinheiro e o principal pressuposto é que este é equivalente geral. É funcional, em Marx, que o dinheiro tenha como origem lógica a mercadoria, para que sua rota direta com o valor não seja travada. Inevitavelmente deve o dinheiro emergir da mercadoria, tendo em vista que é nela, enquanto produto do trabalho humano abstrato, que o valor está incorporado (NELSON, 2001, p.50; SHUKLIAN, 2000, p.5).

A mercadoria é, em Marx, uma categoria social e filosófica única, enquanto produto do trabalho humano alienado, que fez do trabalho vivo extraído da força de trabalho a fonte última do valor, no capitalismo. Este trabalho humano tem um caráter duplo, a saber, o trabalho concreto, que é definido como o produtor de valores de uso, e o trabalho abstrato, trabalho socialmente igualado, que é derivado como substância do valor, a propriedade comum das mercadorias que determina seus valores de troca. Valor de uso é particular, mas o valor é geral; como valor, mercadorias são qualitativamente iguais, perfeitamente divisíveis, homogêneas; como valor de uso elas são qualitativamente diferentes, imperfeitamente divisíveis, heterogêneas. Dinheiro e preço são definidos respectivamente como forma necessária da aparência do trabalho abstrato e a expressão do TTSN. Assim, esse trabalho concreto, trabalho particular e privado de diversos 
produtores, necessita de reconhecimento como trabalho social que se completa na medida em que as trocas se desenvolvem. A generalização das trocas estabelece a pari passu 0 trabalho abstrato, a substância social, conduzindo a forma do valor de sua constituição mais simples até a mais desenvolvida, a saber, a forma dinheiro. Só assim é possível equiparar o trabalho dos diversos produtores, igualando os valores de suas mercadorias ao dinheiro. Desse modo, é imperiosa e não vacilante a definição de Marx do valor como produto do trabalho humano objetivado nas mercadorias, entendido de forma igual, geral, comum (NELSON, 2005, p.68; MOSELEY, 2010, p.3-5; BORGES NETO, 2001, p.2 e 7; ITOH\&LAPAVITSAS, 1999, p.33).

Tendo em vista que o valor tem o trabalho abstrato por sua substância e o TTSN como sua magnitude, por que ele não se expressa diretamente no tempo de trabalho? Para Borges Neto (2001, p.3), o valor de troca é a resposta teórica para tal problema. Na medida em que o valor tem que ser expresso em algo diferente dele, já que ele não é visível, não existe materialmente e só se manifesta socialmente, na transação entre duas ou mais mercadorias. Germer (1997, p.111-2), por sua vez, semelhante a Borges Neto, apresenta dois aspectos:

\begin{abstract}
"[Primeiro], o trabalho em si não existe como objeto ou coisa, mas apenas como atividade em processo de realização. Terminado o processo de produção, encerrou-se também a atividade do trabalho e dele nada mais resta, exceto o seu produto. [...] [Segundo], a quantidade de trabalho materializado no valor de uso de cada mercadoria é um trabalho individual, de tipo particular, portanto não expressa diretamente trabalho social. [...] para uma mercadoria ser trocada pelo produto de outro trabalho particularizado, ambas devem converter-se em - ou devem legitimar-se como - expressões de trabalho social ou abstrato, e isso só é possível se puderem traduzir-se em um produto do trabalho convertido pelo processo das trocas em expressão do trabalho social em oposição aos trabalhos particulares. Esta mercadoria, que é o dinheiro, reveste-se não só da materialidade de todos os produtos do trabalho, mas é ao mesmo tempo apenas um símbolo no qual o conjunto dos produtores representa o trabalho na sua dimensão social".
\end{abstract}

Nesse sentido, Nelson (2001, p.44), afirma que valor em Marx é trabalho objetivado e alienado nas mercadorias, aparecendo na circulação como valor de troca e tornando-se independente no dinheiro, a forma de aparência do valor. Dinheiro, desse modo, é necessário para que as mercadorias sejam trocadas e também para generalizar a produção delas. Para Shuklian (2000, p.5), na medida em que o valor pode ser manifestar apenas indiretamente numa relação entre mercadorias, ao invés de diretamente como relação socioeconômica entre seres humanos, 0 processo de coordenação do trabalho dos produtores independentes com 0 trabalho da sociedade em geral é estabelecido apenas mediante a troca de mercadorias. Isto implica que, para qualquer mercadoria, seu valor deve ter uma forma de expressão social independente, pois nenhuma mercadoria pode expressar seu valor. 


\section{A ORIGEM DO DINHEIRO E O PROCESSO DE TROCA}

Conforme Lapavitsas (1991, p.296), o dinheiro origina-se de modo espontâneo no processo de troca. Borges Neto (2001, p.3-5), por sua vez, diz que, na medida em que as trocas eventuais se generalizaram, o produto do trabalho humano transformava-se em mercadorias. É dessa ação que surge o dinheiro. 0 processo de troca, dessa forma, resume-se a equivalência dos diversos produtos do trabalho humano ao dinheiro, dando-lhes a forma de mercadorias. Concomitantemente, o trabalho realizado na produção destas, que é individual, privado, concreto, assume o caráter de trabalho geral, comum, abstrato. Ou seja, assim como afirma Lapavitsas (1991) e Shuklian (2000), a emergência do dinheiro ocorre vis-à-vis o desenvolvimento do processo de produção e troca de mercadorias. Ainda assim, para Germer (2005, p.33), a definição do dinheiro parte da natureza mercantil da economia, ou seja, da esfera da circulação, e não de sua natureza capitalista, nesse caso, a natureza da constituição interna das unidades de produção, não afetando, assim, a natureza do dinheiro.

A natureza peculiar da mercadoria sintetiza uma contradição: ao mesmo tempo em que é um produto que visa atender as necessidades específicas deve ter características comuns. Para Rosdolsky (2001, p.112), isto expressa que, na ordem capitalista, o trabalho particular, individual, não pode ser (e nem é) diretamente social, devendo atestar-se enquanto tal, por sua própria negação, negando sua origem. A cega ação das forças do mercado (sendo esta a forma única de vinculação social) subsume a produção social, transformando a dependência recíproca dos produtores num fato, no movimento geral de sua ordem e desordem. É esta natureza, que imputa à mercadoria se igualar a todas as outras, mesmo sendo específica e particular, que lhe dota de trabalho abstrato.

Segundo Moseley (2005, p.2), o que torna a mercadoria igual às outras, na prática, são as quantidades de trabalho abstrato incorporado, sendo que elas devem ser observáveis e comparáveis numa mesma forma objetiva e reconhecida socialmente. Entrementes, a priori não há como serem diretamente observáveis as quantidades de trabalho abstrato contido nas mercadorias. Porém, estas podem adquirir uma "forma de aparência" material, no qual torna-as observáveis e comparáveis objetivamente. É assim que emerge o dinheiro, enquanto necessidade de existência de uma forma comum de expressão das quantidades de trabalho abstrato incorporado nas mercadorias.

Simultaneamente, a origem do dinheiro resulta da divisão da mercadoria, o produto do trabalho humano, em valor de uso e valor de troca. É por essa razão que as trocas bilaterais ou escambo sucumbem, na medida em que cada mercadoria tenta ser a pari passu tanto valor de 
uso quanto valor de troca. Esse colapso é dirimido ao passo que uma mercadoria passa a representar o valor em geral para todas as outras. Isto provoca uma interação espontânea de todas as outras mercadorias, isolando a mercadoria dinheiro, que surge como representação do valor. O desenvolvimento do dinheiro, então, progride simultaneamente com evolução da produção de mercadorias e o processo de troca. Ao longo do tempo, o dinheiro se torna o vínculo de todo o sistema de relações produtivas humanas da sociedade capitalista. 0 processo de troca, assim, imputa a necessidade de escolher uma mercadoria, dentre todas, que expresse 0 valor de todas as outras, que se torne a encarnação direta do trabalho social e que, por isso, se torna direta e incondicionalmente intercambiável por todas as mercadorias. Porém, tanto a mercadoria quanto o dinheiro participam do intercâmbio em condições diferentes. Enquanto aquela é objeto de uso, quer seja como meio de consumo quer seja como meio de produção, esta, por sua vez, não é nem uma coisa nem outra. Por isso, dinheiro e mercadoria não ocupam posições simétricas no processo de circulação (SHUKLIAN, 2000, p.7; ITOH\&LAPAVITSAS, 1999, p.33; ROSDOLSKY, 2001, p. 115, CUTLER, 1981, p. 56-7).

\begin{abstract}
"A constante repetição da troca transforma-a em um processo social regular. Com o correr do tempo, torna-se necessário, portanto, que parte do produto do trabalho seja intencionalmente feita para a troca. A partir desse momento, consolida-se, por um lado, a separação entre a utilidade das coisas para as necessidades imediatas e sua utilidade para a troca. Seu valor de uso dissocia-se de seu valor de troca. Por outro lado, tornase a relação quantitativa, em que se trocam, dependente de sua própria produção. 0 costume fixa-as como grandezas de valor" (BORGES NETO, 2001, p.7).
\end{abstract}

Tão logo, é perceptível que o dinheiro surge como resposta à contradição intrínseca na mercadoria, isto é, entre sua natureza como produto e seu caráter geral como valor de troca, porém não a supera. Rosdolsky (2001, p.120-1) e Cutler (1981, p.64) afirmam que, conforme 0 dinheiro enquanto mercadoria distinta se autonomiza, tonando-se a forma independente do valor - exterior à própria mercadoria -, o processo de troca entre mercadoria e dinheiro fica a mercê de condições externas, que podem ou não ocorrer. $\mathrm{O}$ ato da troca multilateral ou monetária executa dois movimentos independentes, a saber, venda ou troca de mercadoria por dinheiro e a compra ou a troca de dinheiro por mercadoria. Esses movimentos implicam na mudança de forma (transformação) do valor, saindo da forma mercadoria e indo para forma dinheiro e vice-versa.

Os dois movimentos da troca monetária podem estar espacial e temporalmente separados entre si, ou seja, podem ser não contemporâneos e ter sua identidade imediata obliterada, no caso, uma mercadoria trocada ao mesmo tempo por outra. Em função disso, o ato que visa a troca em si, isto é, obter dinheiro, separa-se da troca que objetiva obter valores de uso, ou seja, que almeja o consumo. Esta é a razão da discrepância entre a troca comercial e a troca que objetiva 
o consumo, pois a produção, que sofre e gera essa desarmonia², funciona diretamente para 0 comércio e só indiretamente para o consumo (ROSDOLSKY, 2001, p.120-1; CUTLER, 1981, p.64).

A mercadoria possui a capacidade de troca é por ser específica, ter particularidade, ser desejável e satisfazer necessidades peculiares e concretas, ou seja, ter valor de uso. Assim ela deve possuir características próprias que a distinga de todas as outras. Porém, não é por sua natureza específica ou concreta que torna o produto do trabalho humano mercadoria, todavia por causa do seu caráter geral, similar e abstrato, ter valor. Uma mercadoria é um produto que sintetiza elementos distintos e contraditórios entre si, pois ela tem uma dimensão peculiar e concreta e, ao mesmo tempo, outra que é geral e abstrata. Só nas trocas multilaterais ou monetárias, quando o valor é expresso enquanto valor de troca, é que a contradição se materializa e pode ser resolvida. $O$ dinheiro surge espontaneamente como resposta para essa contradição, tendo em vista que a sua forma de existência social está dissociada da sua existência natural. Ele aparece como materialização das trocas, como expressão do valor das mercadorias e surge não apenas almejando facilitar as trocas, porém como solução endógena da contradição entre a natureza particular e concreta da mercadoria e sua característica comum, geral e abstrata. Não obstante, a emergência do dinheiro não implica na superação dessa contradição, contudo cria as respostas e as formas de no qual ela pode mover-se (ROSDOLSKY, 2001, 106-121).

Carvalho (2011, p.27) destaca que essa natureza dupla e contraditória da mercadoria, ou seja, possuir natureza concreta, valor de uso e, ao mesmo tempo, um caráter geral, valor que se expressa no valor de troca, não se manifesta nas trocas bilaterais ou escambo, posto que, neste caso, valor de uso e valor de troca são análogos. Com o desenvolvimento do sistema mercantil, os produtores individuais ampliam a sua dependência aos demais produtores, no intento de satisfazer suas necessidades. É aí que as duas formas de valor se diferencia, na medida em que o valor de uso, enquanto manifestação da materialidade da mercadoria, existe por si só, o valor de troca necessita de sanção social. É por isso que, segundo Cutler (1981, p.60), a existência do dinheiro é condição sine qua non apenas para um tipo transação, a saber, a troca monetária. Essa forma de intercâmbio é necessária para que grande parte dos tipos de divisão do trabalho e da especialização fundada na produção de mercadorias exista. Conforme Rosdolsky (2001, p. 106), esse tipo de troca é, em essência, "uma relação abstrata entre propriedades privadas, entre 0 direito de propriedade, sendo que essa relação abstrata é a forma do valor, cuja sua existência concreta é o dinheiro", que se escamoteia numa relação entre indivíduos.

\footnotetext{
2 Pode-se afirmar que essa desarmonia também é válida para o crédito.
} 
Para Borges Neto (2001, p.6), a troca monetária é, portanto, um processo múltiplo que transforma os produtos do trabalho em mercadorias e a transforma as mercadorias em dinheiro. Não é de se surpreender, como aborda Foley $(1983$, p.5), que em sociedades onde as trocas são generalizadas, o valor assuma uma forma independente como dinheiro, como expressão geral das trocas. No entanto, Lapavitsas (1991, p.298) afirma que nesse processo, o movimento essencial é a circulação de mercadorias, tendo em vista sua condição imperiosa para a reprodução material da sociedade. A circulação de dinheiro é, assim, um movimento subordinado, deduzido das trocas primárias do valor na forma de mercadorias. Nesse sentido, Nelson $(2005$, p.72) assevera que não existe dinheiro ou expressão do valor sem trocas, ainda que elas, em si, não o produzam. As transações possuem uma dependência da dinâmica fundamental relacionada à produção e circulação de mercadorias.

A troca bilateral ou escambo, analisa Cutler (1981, p.64), significa a existência de circuitos, no qual um lado associa-se diretamente a outro (seu duplo), que implica em diversas transações isoladas e não-relacionadas entre pares de produtores privados. Entretanto, a troca multilateral ou monetária, não implica numa "coleção de pares de transações isoladas", pois ela, enquanto um circuito (M-D-M), se sobrepõe parcialmente a duas fases (venda [M-D] e compra [D-M]), relacionando-se assim "direta ou indiretamente com todos os outros". Dessa forma, a transação monetária implica numa rede interligada de trocas. Por isso que, segundo Reuten (1988, p.126), a troca monetária é pressuposto para a existência do capitalismo, pois este é um sistema no qual as unidades de produção e de consumo são separadas. A troca monetária alinha a produção ao consumo, sendo que aquela é condição de existência da associação destas.

A interdependência entre transações, na troca monetária, deriva da separação entre vendas (M-D) e compras (D-M). A separação do circuito de troca em duas fases implica numa aumento das possibilidades de troca. As trocas bilaterais, ou escambo, são limitadas às transações nas quais cada vendedor no momento em que compra as mercadorias de outro vende as suas próprias. Essa restrição no intercâmbio é eliminada a partir do momento em que o dinheiro é introduzido e, com isso transações multilaterais tornam-se realizáveis. Este efeito do dinheiro é deveras importante, porém depende das relações sociais de produção. As transações monetárias são imprescindíveis para que a divisão social do trabalho e a especialização baseada no intercâmbio de produtos passem a existir. A divisão do trabalho, no capitalismo, abrange transações monetárias e, como desdobramento, não pode prescindir da existência do dinheiro (CUTLER, 1981, p. 64-5).

Para Cutler (1981, p.66), a introdução do dinheiro no intercâmbio implica na sua separação espacial e temporal. A separação espacial das trocas diz que um agente econômico vende suas 
mercadorias a outros e compra mercadorias de distintos agentes, não sendo ele obrigado a comprar de quem vendeu, diferentemente do que acontece no escambo. Assim, é possível abordar a existência de uma mercadoria para um dado produto, já que o agente econômico deve ter a liberdade para vender sua mercadoria exatamente a quem a deseja comprar. A separação temporal, por sua vez, quer dizer que as vendas de um agente econômico não ocorre a pari passu de suas compras. Como importante desdobramento da separação temporal, o processo de circulação passa a possuir uma dimensão de tempo, isto é, existe, "associado a cada circuito, um período de tempo para que as mercadorias sejam transferidas". Outro resultado dessa separação, que se torna uma característica da troca monetária, é a falta de sincronia entre compras e vendas de um agente econômico. Este hiato temporal é ocupado pelo dinheiro, ou seja, o dinheiro é o elo que unifica compras e vendas temporalmente. A retirada teórica desse hiato, como feito pela teoria convencional, "significa a eliminação do espaço para a existência do dinheiro".

\section{UMA POLÊMICA}

Uma linha marxista interpretativa sobre esta temática que dessoa da síntese apresentada até aqui é exposta por Reuten (1988), que ficou conhecida como a abordagem da forma-valor. Para ele, o trabalho abstrato não presume-se existir como quantidade do TTSN, logo haveria uma vacância em Marx no que tange a uma teoria quantitativa do valor-trabalho. Moseley (2010, p.17), por sua vez, critica duramente essa esta interpretação, apontando-a como "altamente especulativa" e afirmando que Reuten não apresenta qualquer evidência textual dos capítulos pertinentes n'O Capital que subsidie sua interpretação.

Reuten (1988) afirma que o trabalho abstrato contido nas mercadorias possui somente uma dimensão qualitativa, sendo impossível haver relações quantitativas entre mercadorias sem a presença do dinheiro. Moseley (2010), por sua vez, referenciando Marx afirma que há no valor uma dimensão quantitativa, porém ela é invisível. Para ele, a necessidade do dinheiro surge do fato de que a quantidade de trabalho abstrato objetivado contido nas mercadorias não é diretamente observável, como tempo de trabalho. O dinheiro é derivado como a forma necessária da aparência do tempo de trabalho abstrato socialmente necessário contido nas mercadorias. Quantidades de dinheiro, ou preços, são a forma necessária da aparência das quantidades tempo de trabalho abstrato socialmente necessário. O dinheiro, assim, habilita-se a tornar o invisível, visível.

O caminho da investigação de Marx, assevera Moseley (2010, p.6-7), o conduziu a retornar ao valor de troca, enquanto o modo necessário de expressão ou forma de aparência da 
substância do valor, do trabalho abstrato objetivado. A quantidade do trabalho abstrato contido numa dada mercadoria é expressa objetivamente enquanto quantidade de outra mercadoria que é equiparada, pois contém a mesma quantidade de trabalho abstrato. As características específicas do trabalho abstrato, a saber, qualidade homogênea e quantidades definidas, determinam as características necessárias da forma de aparência do valor, ou dinheiro. A forma simples do valor é "insuficiente" e a forma expandida do valor é "imperfeita" exatamente porque essas formas do valor não expressam adequadamente as características da substância do valor, o trabalho abstrato. $O$ trabalho abstrato contido nas mercadorias deve ser expresso não apenas qualitativamente, enquanto o mesmo tipo de trabalho, mas também quantitativamente, enquanto quantidades definitivas desse trabalho humano igual. $O$ trabalho abstrato é a uma quantidade e, portanto, sua forma objetiva de aparência também deve ser uma quantidade.

"[T]he magnitude of the value of both commodities (the labor-times required to produce them) is a "given quantity", "independently of its value-form", and the proportions in which the two are exchangeable are determined by the ratio of these two given magnitudes" (MOSELEY, 2010, p.9).

Reuten (1988) afirma que no cap.1 d'O Capital a forma do dinheiro é abordada, entretanto o dinheiro em si, ou seja, sua existência sistemática, não o é, sendo feito apenas no cap.3. Moseley (2010, p.17), por sua vez, localiza este entendimento como outra interpretação equivocada. Segundo ele, Reuten não explica a distinção entre "abordar a forma do dinheiro" e "derivar a existência sistemática". É notório, para ele, que no Cap.1 o dinheiro é derivado como a forma necessária da aparência do trabalho abstrato e do TTSN. Dessa forma, Marx teria abordado de modo suficiente a "existência sistemática" do dinheiro.

Foley (1983, p.8-9), convergindo com o pensamento de Moseley (2010), assevera que o valor é inerentemente quantitativo, porém a sua expressão só ocorre comparativamente, carecendo assim a existência de um equivalente geral. Além disso, para o autor, entender a relação quantitativa existente implica acreditar que o tempo de trabalho social regula ou determina o valor agregado do dinheiro. E o resultado prático dessa mensuração pode ser "to get some insight into limits to the rate of exploitation and therefore the magnitude of surplus value that a capitalist economy might generate" (FOLEY, 2005, p.39).

Nesse sentido, Foley (2005, p.39) acredita ser apropriado quantificar a relação entre tempo de trabalho e dinheiro, tendo em vista que, para ele, o próprio Marx deu um significado quantitativo a essa relação. Isto implica, nos seus termos, compreender que, 
division of labour. This observation calls into question the relevance of comparing social labour-time in capitalism with the social labour-time that might emerge under socialism (FOLEY, 2005, p.39).

\section{CONCLUSÃO}

Este trabalho apresentou as controvérsias existentes no programa de pesquisa marxista no tocante à natureza do dinheiro, isto é, demonstrou 0 atual estado das artes sobre as questões elementares do dinheiro nas abordagens marxistas. A partir da exposição dos consensos e dissensos contidos no bojo da literatura aqui utilizada é que foi possível empreender tal tarefa.

A análise do dinheiro em Marx parte de um momento teórico indispensável, isto é, o de se distinguir a definição do dinheiro apresentada na circulação mercantil simples, no qual as relações capitalistas ainda não estão plenamente desenvolvidas, e na circulação capitalista. Naquela, a dedução lógico-histórica pressupõe que: os produtores sejam autônomos e independentes e donos dos meios de produção; exista o reconhecimento social da propriedade privada dos meios de produção e do produto; as trocas são realizadas através das trocas voluntárias nos mercados; os contratos sejam o instrumento jurídico que regula as trocas entre os agentes econômicos e; consequentemente, o produto do trabalho humano pode aparecer como mercadoria (sejam úteis e tenham valor). $O$ capitalismo, por sua vez, possui todas as relações pressupostas na circulação simples, mas com uma distinção: há uma divisão de classe entre os proprietários dos meios de produção e os proprietários da força de trabalho. Este elemento é vital e submete todos os outros à sua lógica, visto que possibilita a emergência do capital, um valor dinâmico, que muda de forma e na produção se auto expande. Por isso, no capitalismo a circulação aparece como uma das fases do processo de produção, diferentemente do que ocorre na circulação simples. É nesse sentido que a análise do dinheiro no capitalismo deve, inequivocamente, ser diferenciada, algo que já que foi ofertado por Marx. Aqui se concorda com Germer (1997, p.108), quando ele afirma que uma omissão recorrente entre os marxistas é "não levar em conta as conexões e diferenças entre os conceitos de dinheiro e capital".

O conceito de dinheiro e de moeda no programa de pesquisa marxista esta intrinsecamente ligado à teoria do valor. Não há como ter outro ponto analítico originário, dentro do programa marxista, para se estudar o dinheiro que não seja esse. Por isso, a teoria do valor é necessariamente a baliza fundante para investigar os fenômenos econômicos em geral e monetários em específico. A gênese do dinheiro deriva-se necessariamente da mercadoria e do sistema de trocas. Por isso, além de um caráter lógico, o entendimento sobre a emergência do dinheiro deve ter uma dimensão histórica, já que a mercadoria tem existência historicamente determinada. 
E nesse sentido, aqui se entende que o programa de pesquisa marxista considera 0 dinheiro como expressão da relação social vendedor-comprador, assim como a forma material de aparência do valor ou riqueza abstrata. Isto fornece ao dinheiro um status teórico-conceitual que apreende diversos elementos, no qual a teoria monetária não marxista é impossibilitada de captar. Só é possível desenvolver o conceito valor de troca quando se considera o dinheiro como algo que vai além de um mero símbolo.

\section{REFERÊNCIAS BIBLIOGRÁFICAS}

ASTARITA, Rolando. Concepciones sobre el Dinero, el Rol del Oro y Cuestiones Monetarias. IADE/Realidad Económica, 2006.

BORGES NETO, J. M. Por que o Dinheiro é um Problema para a Economia Neoclássica? Uma Interpretação a Partir de Marx. 2001. p.23. Texto para Discussão, n. 08/2001. PEPGEP _ PUC/SP, 2001.

BRUNHOFF, Suzanne de. A moeda em Marx. Rio de Janeiro: Paz e Terra, 1978.

BRUNHOFF, Suzanne de. Marx's Contribution to the Search for a Theory of Money. In: MOSELEY, Fred (ed.). Marx's Theory of Money: Modern Appraisals. London: Palgrave, 2005.

CUTLER, Antony, et al. 0 capital de Marx e o capitalismo de hoje. Volume II. Rio de Janeiro: Zahar Editores, 1981.

FOLEY, Duncan K. On Marx's Theory of Money. Social Concept, v.1 n.1, p. 5-19, 1983.

FOLEY, Duncan. Marx's Theory of Money in Historical Perspective. In: MOSELEY, Fred (ed.). Marx's Theory of Money: Modern Appraisals. London: Palgrave, 2005.

GERMER, Claus M. Componentes estruturais da teoria do dinheiro no capitalismo. Revista da Sociedade Brasileira de Economia Política, v. 1, n. 1, p. 106-33, 1997.

GERMER, Claus M. The Commodity Nature of Money in Marx's Theory. In: MOSELEY, Fred (ed.). Marx's Theory of Money: Modern Appraisals. London: Palgrave, 2005.

ITOH, M., LAPAVITSAS, C. Political Economy of Money and Finance. New York: St. Martin's Press, 1999.

KLAGSBRUNN, Victor H. Considerações sobre a categoria dinheiro de crédito. Ensaios FEE. Porto Alegre, v. 13, n. 2, p. 592-615, 1992.

LAPAVITSAS, Costas. The theory of credit money: a structural analysis. Science and Society, v.55, n.3, p.291-322, 1991.

LAPAVITSAS, Costas. The social relations of money as universal equivalent: a response to Ingham. Economy and Society, v. 34, n.3, p. 389-403, ago. 2005.

MOSELEY, Fred. Introduction. In: MOSELEY, Fred (ed.). Marx's Theory of Money: Modern Appraisals. London: Palgrave, 2005.

MOSELEY, Fred. Marx's theory of money as the measure of value: a critique of Reuten's interpretation "Value-Form" Interpretation of Part 1 of Volume 1 of Capital. Texto para discussão. Mount Holyoke College, p.41. Disponivel em: http://www.mtholyoke.edu/ fmoseley/Working_Papers_PDF/measure.pdf. Acesso em: 13 de maio de 2010.

MURRAY, Patrick. Money as displaced social form: why value cannot be independent of price. In: MOSELEY, Fred (ed.). Marx's Theory of Money: Modern Appraisals. London: Palgrave, 2005. NELSON, Anitra. Marx's Theory of the Money Commodity. History of Economics Review. V.33, p.44-63, 2001.

NELSON, Anitra. Marx's Objections to Credit Theories of Money. In: MOSELEY, Fred (ed.). Marx's Theory of Money: Modern Appraisals. London: Palgrave, 2005. 
PAULANI, Leda M. A Autonomização das Formas Verdadeiramente Sociais na Teoria de Marx: Comentários sobre o Dinheiro no Capitalismo Contemporâneo. Revista EconomiA, Brasília, v. 12, n.1, p. 49-70, jan-abr, 2011.

REUTEN, Geert. The money expression of value and the credit system: a value-form theoretic outline. Capital and Class. Londres, n. 35, p.121-142, 1988.

ROSDOLSKY, Roman. Gênese e estrutura de 0 Capital de Karl Marx. Rio de Janeiro: Contraponto, UERJ, 2001.

SHUKLIAN, Steve. Karl Marx on the Foundations of Monetary Theory. Texto para discussão. Lewis College of Business, Marshall University, 2000. Disponível em: http://www.marshall.edu/cber/research/working/wp00-02-a.PDF. Acesso em: 15 de abril de 2010.

Recebido em Agosto de 2020.

Aceito para Publicação em Outubro de 2020. 


\title{
ORIGEM E DESENVOLVIMENTO LÓGICO DO DINHEIRO: CONTROVÉRSIAS MARXISTAS
}

\begin{abstract}
Resumo
O texto objetiva: i) comparar a leitura de diversos intérpretes marxistas que trabalham com a categoria dinheiro, sobretudo como se compreende sua origem e desenvolvimento; ii) delimitar um espaço teórico para a exposição de uma teoria monetária especificamente marxista e; iii) mostrar 0 atual estado das artes desta teoria. Para isso, necessário se faz localizar as aproximações e divergências conceituais, centrando-se na formulação da origem lógico-histórica do dinheiro, mediante a definição e precisão do conceito, o que se entende por valor e mercadoria e a relação do dinheiro no processo de troca. Para apresentar as similitudes e dissimilitudes dos argumentos dos diversos autores, o caminho aqui percorrido não apenas apontou o que fala cada um deles, porém "os colocou para dialogar". Em síntese, o texto expõe as posições que aqui se entende como as mais significativas sobre questões elementares do dinheiro, dentro do marxismo.
\end{abstract}

Palavras-chaves: Dinheiro; Valor; Teoria Monetária Marxista

\section{ORIGIN AND LOGICAL DEVELOPMENT OF MONEY: MARXISTS CONTROVERSY}

\begin{abstract}
This paper aim: i) to compare the reading of more important Marxist that working with the money category, especially as understanding its origin and development; ii) to define a theoretical space for the exhibition of a monetary theory properly Marxist; iii) to show the present state of the arts of this theory. For this, it is necessary to find conceptual similarities and differences, focusing on the formulation of logical-historical origin of money, by definition of concept, what is meant by value and merchandise and the relationship of the money in the process of exchange. To introduce the similarities and dissimilarities of the arguments of several authors, the path traveled here not only showed the speech that each of them, but "put them to dialogue." In short, this paper exposes the positions that here is understood as the most significant on basic issues of money, within Marxism. Keywords: Money; Value; Monetary Theory Marxist JEL Classification: B51.
\end{abstract}

